\title{
The Theranostic PSMA Ligand PSMA-617 in the Diagnosis of Prostate Cancer by PET/CT: Biodistribution in Humans, Radiation Dosimetry, and First Evaluation of Tumor Lesions
}

\author{
Ali Afshar-Oromieh ${ }^{1,2}$, Henrik Hetzheim ${ }^{3}$, Clemens Kratochwil ${ }^{1}$, Martina Benesova ${ }^{4}$, Matthias Eder ${ }^{4}$, Oliver C. Neels ${ }^{4}$, \\ Michael Eisenhut ${ }^{4}$, Wolfgang Kübler ${ }^{5}$, Tim Holland-Letz ${ }^{6}$, Frederik L. Giesel ${ }^{1}$, Walter Mier ${ }^{1}$, Klaus Kopka ${ }^{4}$, \\ and Uwe Haberkorn ${ }^{1,2}$ \\ ${ }^{1}$ Department of Nuclear Medicine, Heidelberg University Hospital, Heidelberg, Germany; ${ }^{2}$ Clinical Cooperation Unit Nuclear \\ Medicine, German Cancer Research Center, Heidelberg, Germany; ${ }^{3}$ Division of Medical Physics in Radiology, German Cancer \\ Research Center, Heidelberg, Germany; ${ }^{4}$ Division of Radiopharmaceutical Chemistry, German Cancer Research Center, Heidelberg, \\ Germany; ${ }^{5}$ Division of Radiation Protection and Dosimetry, German Cancer Research Center, Heidelberg, Germany; and \\ ${ }^{6}$ Department of Biostatistics, German Cancer Research Center, Heidelberg, Germany
}

PET imaging with the prostate-specific membrane antigen (PSMA)targeted radioligand ${ }^{68} \mathrm{Ga}-\mathrm{PSMA}-11$ is regarded as a significant step forward in the diagnosis of prostate cancer (PCa). More recently, a PSMA ligand was developed that can be labeled with ${ }^{68} \mathrm{Ga},{ }^{111} \mathrm{In}$, ${ }^{177} \mathrm{Lu}$, and ${ }^{90} \mathrm{Y}$. This ligand, named PSMA-617, therefore enables both diagnosis and therapy of PCa. The aims of this evaluation were to clinically investigate the distribution of ${ }^{68} \mathrm{Ga}-\mathrm{PSMA}-617$ in normal tissues and in PCa lesions as well as to evaluate the radiation exposure by the radioligand in PET imaging. Methods: Nineteen patients, most of them with recurrent $\mathrm{PCa}$, were referred for ${ }^{68} \mathrm{Ga}-\mathrm{PSMA}-617 \mathrm{PET} /$ CT. The quantitative assessment of tracer uptake of several organs and of 53 representative tumor lesions was performed in 15 patients at 1 and $3 \mathrm{~h}$ after injection. In 4 additional patients, the same procedure was conducted at $5 \mathrm{~min}, 1 \mathrm{~h}, 2 \mathrm{~h}, 3 \mathrm{~h}, 4 \mathrm{~h}$, and $5 \mathrm{~h}$ after injection. On the basis of the data for these 4 patients (mean injected dose, 231 $\mathrm{MBq}$ ), the radiation exposure of a ${ }^{68 \mathrm{Ga}-P S M A-617 ~ P E T / C T}$ was identified. Results: Intense tracer uptake was observed in the kidneys and salivary glands. In 14 of 19 patients (73.7\%), at least 1 lesion suspected of being a tumor was detected at $3 \mathrm{~h}$ after injection. Of 53 representative tumor lesions selected at $3 \mathrm{~h}$ after injection, 47 lesions were visible at $1 \mathrm{~h}$ after injection. The mean tumor-to-background ratio for maximum standardized uptake value was $20.4 \pm 17.3$ (range, 2.384.0) at $1 \mathrm{~h}$ after injection and $38.2 \pm 38.6$ (range, 3.6-154.3) at $3 \mathrm{~h}$ after injection. The average radiation exposure (effective dose) was approximately $0.021 \mathrm{mSv} / \mathrm{MBq}$. Conclusion: Within healthy organs, the kidneys and salivary glands showed the highest ${ }^{68} \mathrm{Ga}-\mathrm{PSMA}-617$ uptake. The radiation exposure was relatively low. ${ }^{68} \mathrm{Ga}-\mathrm{PSMA}-617$ shows $\mathrm{PCa}$ lesions with high contrast. Images obtained between 2 and $3 \mathrm{~h}$ after injection seem to be the best option with regard to radiotracer uptake and tumor contrast. Later images can help to clarify unclear lesions.

Key Words: prostate cancer; PET/CT; positron emission tomography; PSMA; prostate-specific membrane antigen; dosimetry

J Nucl Med 2015; 56:1697-1705

DOI: 10.2967/jnumed.115.161299

\footnotetext{
Received May 23, 2015; revision accepted Aug. 4, 2015.

For correspondence contact: Ali Afshar-Oromieh, Department of Nuclear Medicine, INF 400, 69120 Heidelberg, Germany.

E-mail: a.afshar@gmx.de

Published online Aug. 20, 2015.

COPYRIGHT @ 2015 by the Society of Nuclear Medicine and Molecular Imaging, Inc.
}

$\mathbf{P}$ rostate cancer $(\mathrm{PCa})$ is the most common malignant tumor in men worldwide $(1,2)$. After initial therapy, mainly by surgery or radiation, biochemical recurrence is frequent. At this constellation, searching for tumor relapses and metastases is challenging for conventional imaging modalities such as CT and MR imaging because of the often unsatisfying sensitivity and specificity. As a consequence, there has been the need to develop improved techniques to image PCa. In this context, many groups have focused on the prostate-specific membrane antigen (PSMA) as a promising biologic target for scintigraphic imaging and endoradiotherapy of PCa $(3,4)$. PSMA is a transmembrane protein that is significantly overexpressed in most adenocarcinomas of the prostate gland, compared with other PSMA-expressing tissues. In addition, as already shown in the late 1990s, the neovasculature of many solid tumors also expresses PSMA (5-7).

During the last 2 decades, many efforts have been undertaken to develop PSMA ligands (8-16). One of these ligands, the smallmolecule Glu-NH-CO-NH-Lys-(Ahx)-[ $\left.{ }^{68} \mathrm{Ga}(\mathrm{HBED}-\mathrm{CC})\right]$, also known as PSMA-11, PSMA ${ }^{\mathrm{HBED}}$, Glu-CO-Lys(Ahx)-HBED-CC, DKFZ-PSMA-11, PSMA-HBED-CC, PSMA-HBED, PSMA, or Prostamedix, developed at the German Cancer Research Center Heidelberg (DKFZ), has become the most clinically used radiotracer. This compound shows a strong binding affinity to PSMA and a highly efficient internalization into PCa cells $(17,18)$.

The hitherto existing results of PET/CT imaging with ${ }^{68} \mathrm{Ga}-$ PSMA-11 demonstrate that this method could be a significant step forward in the diagnosis of recurrent PCa (19-23).

Meanwhile, modifications of PSMA-11 have resulted in the development of a novel small-molecule PSMA ligand, PSMA-617. In preclinical studies, this ligand showed a significantly improved binding affinity to PSMA and a highly efficient internalization into PCa cells (24). PSMA-617 can be labeled with ${ }^{68} \mathrm{Ga},{ }^{177} \mathrm{Lu},{ }^{111} \mathrm{In}$, and ${ }^{90} \mathrm{Y}$ and, therefore, be used for PET imaging as well as for radioligand-based therapy. Preclinical assays of PSMA-617 showed inhibition constant $\left(K_{i}\right)$ values of $2.3 \pm 2.9 \mathrm{nM}$, demonstrating a significant improvement, compared with PSMA-11 (12.0 $\pm 2.8 \mathrm{nM})$. To our knowledge, PSMA-617 presents one of the highest binding affinities to the PSMA receptor that have been published thus far. In preclinical studies, tumor-to-background ratios of up to 1,058 were 
TABLE 1

Characteristics of All Patients Investigated in This Study

\begin{tabular}{|c|c|c|c|c|c|c|c|c|c|c|}
\hline $\begin{array}{c}\text { Patient } \\
\text { no. }\end{array}$ & $\begin{array}{l}\text { Age } \\
\text { (y) }\end{array}$ & $\begin{array}{c}{ }^{68} \mathrm{Ga}-\mathrm{PSMA}- \\
617 \\
(\mathrm{MBq})\end{array}$ & $\begin{array}{c}\text { Gleason } \\
\text { score }\end{array}$ & $\begin{array}{c}\text { PSA } \\
(\mathrm{ng} / \mathrm{mL})\end{array}$ & $\begin{array}{l}\text { Previous } \\
\text { treatment }\end{array}$ & $\begin{array}{c}\mathrm{LN} \\
\text { metastases }\end{array}$ & $\begin{array}{c}\text { Bone } \\
\text { metastases }\end{array}$ & $\begin{array}{l}\text { Local } \\
\text { relapse }\end{array}$ & $\begin{array}{l}\text { Soft-tissue } \\
\text { metastases }\end{array}$ & $\begin{array}{c}\text { Primary } \\
\text { tumor }\end{array}$ \\
\hline $1^{*}$ & 66 & 237 & 7 & 0.40 & $R P x+R T$ & 0 & 0 & 0 & 0 & 0 \\
\hline 2 & 55 & 295 & 8 & 6.40 & $\mathrm{RPx}$ & $>10$ & 0 & 0 & 0 & 0 \\
\hline 3 & 73 & 286 & 7 & 10.30 & $\mathrm{RPx}$ & 8 & 0 & 0 & 0 & 0 \\
\hline $4^{*}$ & 49 & 255 & 7 & 0.10 & $R P x+R T$ & 0 & 0 & 0 & 0 & 0 \\
\hline 5 & 69 & 262 & 5 & 1.30 & $R P x+R T$ & 0 & 0 & 1 & 0 & 0 \\
\hline 6 & 71 & 178 & 7 & 4.90 & $\mathrm{RPx}$ & 3 & 0 & 0 & 0 & 0 \\
\hline $7^{\star}$ & 71 & 68 & 7 & 1.30 & $R P x+R T$ & 0 & 0 & 0 & 0 & 0 \\
\hline 8 & 47 & 138 & 6 & 2.81 & RPx & 2 & 0 & 0 & 0 & 0 \\
\hline $9^{*}$ & 64 & 238 & 8 & 0.40 & RPx & 0 & 0 & 0 & 0 & 0 \\
\hline 10 & 60 & 194 & 7 & 2.90 & $\mathrm{RPx}+\mathrm{RT}+\mathrm{ADT}$ & 0 & 0 & 1 & 0 & 0 \\
\hline 11 & 69 & 177 & 8 & 5.16 & $\mathrm{RPx}+\mathrm{RT}+\mathrm{ADT}$ & 0 & 1 & 0 & 0 & 0 \\
\hline 12 & 60 & 151 & 6 & 24.30 & Biopsy & 0 & 0 & 0 & 0 & 1 \\
\hline $13^{\star}$ & 70 & 149 & 7 & 0.22 & RPx & 0 & 0 & 0 & 0 & 0 \\
\hline 14 & 75 & 164 & 7 & 1.40 & $\mathrm{RPx}$ & 0 & 0 & 1 & 0 & 0 \\
\hline 15 & 59 & 132 & 7 & 1.30 & $\mathrm{RPx}+\mathrm{RT}+\mathrm{ADT}$ & 1 & 0 & 0 & 0 & 0 \\
\hline \multicolumn{11}{|c|}{ Dosimetry } \\
\hline 16 & 67 & 260 & 7 & 6.60 & $\mathrm{RPx}+\mathrm{RT}$ & 2 & 0 & 0 & 0 & 0 \\
\hline 17 & 75 & 230 & 9 & 14.91 & $\mathrm{RPx}+\mathrm{ADT}$ & $>10$ & 0 & 0 & 0 & 0 \\
\hline 18 & 61 & 213 & NA & 13.70 & ADT & 0 & 0 & 0 & 0 & 2 \\
\hline 19 & 60 & 221 & NA & 2.86 & $\mathrm{RT}$ & $>10$ & $>10$ & 0 & 0 & 0 \\
\hline
\end{tabular}

observed at $24 \mathrm{~h}$ after injection. In addition, the internalization of the PSMA-617 into the PCa cells is highly effective (internalized fraction: $17.67 \% \pm 4.34 \%$ injected activity $/ 10^{6} \mathrm{LNCaP}$ cells [PSMA-11, $9.47 \% \pm 2.56 \%$ injected activity/106 $\mathrm{LNCaP}$ cells]) $(18,24)$.

Since 2013, ${ }^{177}$ Lu-PSMA-617 has been increasingly used for radioligand therapy of metastatic $\mathrm{PCa}$ patients in several centers (to our knowledge, at least in Bad Homburg, Bonn, Cologne, Freiburg, Heidelberg, Istanbul, Melbourne, LMU Munich, and Münster) (25). However, the performance of this novel theranostic substance in the diagnosis of PCa in humans has not yet been evaluated and published. The aim of this evaluation was to clinically investigate the distribution of ${ }^{68} \mathrm{Ga}-\mathrm{PSMA}-617$ in normal tissues and in PCa lesions as well as to evaluate the radiation exposure by the radioligand in PET imaging.

\section{MATERIALS AND METHODS}

For this evaluation, we performed a retrospective analysis of 19 patients (Table 1) who underwent ${ }^{68} \mathrm{Ga}$-PSMA-617 PET/CT to detect tumor lesions in the case of biochemical relapse of $\mathrm{PCa}$, to exclude metastases before initial treatment of $\mathrm{PCa}$, or to evaluate possible treatment with ${ }^{177} \mathrm{Lu}$-PSMA-617 in progressive disease after multiple pretreatments. The mean age of the patients was $64 \pm 8.2 \mathrm{y}$ (range, 47-75 y; median, $66 \mathrm{y}$ ); patients had a median Gleason score of 7.0 (range, 5-9). The mean prostate-specific antigen (PSA) level was $5.0 \pm$ $6.4 \mathrm{ng} / \mathrm{mL}$ (range, $0.1-24.3 \mathrm{ng} / \mathrm{mL}$; median, $2.9 \mathrm{ng} / \mathrm{mL}$ ).
All patients signed a written informed consent form for the purpose of anonymized evaluation and publication of their data. All reported investigations were conducted in accordance with the Helsinki Declaration and with our national regulations (German Medicinal Products Act, AMG $\S 132$ b). This evaluation was approved by the ethics committee of the University of Heidelberg.

Follow-up was conducted until this article was submitted.

\section{Radiotracer}

The precursor compound PSMA-617 was produced at the German Cancer Research Center as recently published (24). However, the compound is commercially available from $\mathrm{ABX}$ advanced biochemical compounds. The radiopharmaceutical production of ${ }^{68} \mathrm{Ga}$-PSMA-617 was adjusted to good manufacturing practice compliance as previously described for ${ }^{68} \mathrm{Ga}$-PSMA-11 (17).

\section{Imaging}

Images were obtained with ${ }^{68} \mathrm{Ga}$-PSMA-617, which was applied via intravenous bolus injection (mean, $203 \pm 60 \mathrm{MBq}$; range, 68-295 MBq; median, $213 \mathrm{MBq}$ ). Variation of injected radiotracer activity was caused by the short half-life of ${ }^{68} \mathrm{Ga}$ and by variable elution efficiencies obtained during the lifetime of the ${ }^{68} \mathrm{Ge} /{ }^{68} \mathrm{Ga}$ generator. Care was taken that all preparations contained 2 nmol PSMA ligand.

Fifteen patients were investigated with a BIOGRAPH-6 (Siemens). For those patients, an unenhanced CT scan was obtained 1 and $3 \mathrm{~h}$ after tracer injection using the following parameters: slice thickness, $5 \mathrm{~mm}$; increment, $0.8 \mathrm{~mm}$; soft-tissue reconstruction kernel; $130 \mathrm{keV}$ 


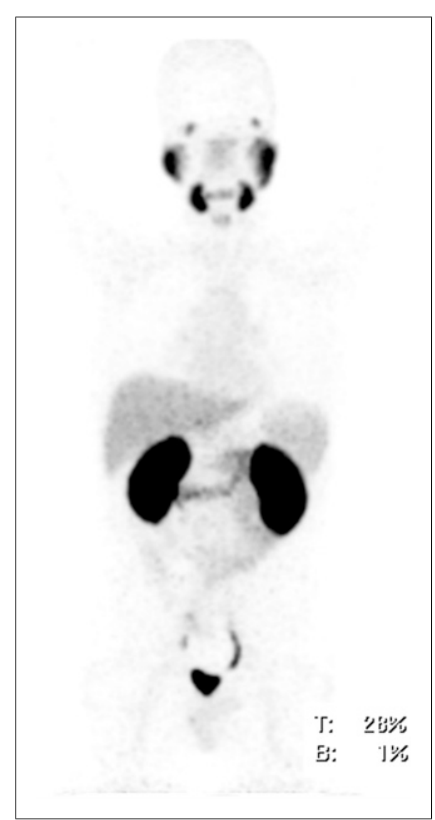

FIGURE 1. Maximum-intensity projections of patient 4 with normal distribution of ${ }^{68} \mathrm{Ga}-\mathrm{PSMA}-617$ at $3 \mathrm{~h}$ after injection. Physiologic accumulation is seen in lacrimal and salivary glands, nasal mucosa, liver, spleen, bowels, and kidneys. Surplus tracer is excreted via urinary tract and urinary bladder. No pathologic tracer uptake was found. and $80 \mathrm{mAs}$. Immediately after CT scanning, whole-body PET was performed in 3-dimensional mode (matrix, $164 \times 164$ ). For each bed position $(16.2 \mathrm{~cm}$; overlapping scale, $4.2 \mathrm{~cm}$ ), a $4-\mathrm{min}$ acquisition time with a $15.5-\mathrm{cm}$ field of view was used. The emission data were corrected for random, scatter, and decay events. Reconstruction was conducted with an ordered-subset expectation maximization algorithm with 2 iterations and 8 subsets and Gauss-filtered to a transaxial resolution of $5 \mathrm{~mm}$ in full width at half maximum. Attenuation correction was performed using the low-dose unenhanced CT data.

Image analysis was performed using an appropriate workstation and software (Syngo TrueD; Siemens).

For the 4 patients who were scanned at 6 different times, we used a BIOGRAPH-mCT PET/ CT scanner (Siemens). An unenhanced $\mathrm{CT}$ scan was obtained at $5 \mathrm{~min}, 1 \mathrm{~h}, 2 \mathrm{~h}, 3 \mathrm{~h}, 4 \mathrm{~h}$, and $5 \mathrm{~h}$ after injection using the following parameters: slice thickness, $5 \mathrm{~mm}$; increment, $2 \mathrm{~mm}$; soft-tissue reconstruction kernel; $120 \mathrm{keV} / 60 \mathrm{mAs}$ at $3 \mathrm{~h}$ after injection and $80 \mathrm{keV} / 30 \mathrm{mAs}$ at $5 \mathrm{~min}, 1 \mathrm{~h}, 2 \mathrm{~h}, 4 \mathrm{~h}$, and $5 \mathrm{~h}$ after injection. Immediately after CT scanning, whole-body PET was performed in 3-dimensional mode (matrix, $200 \times 200$ ). Each bed position (axial field of view, $16.2 \mathrm{~cm}$ ) was acquired for $3 \mathrm{~min}$. The emission data were corrected for random, scatter, and decay events. Reconstruction was conducted with an ordered-subset expectation maximization algorithm with 2 iterations and 8 subsets and Gaussfiltered to a transaxial resolution of $2 \mathrm{~mm}$ in full width at half maximum. Attenuation correction was performed using the low-dose unenhanced CT data.

The 2 different PET/CT scanners (BIOGRAPH-6 and BIOGRAPH$\mathrm{mCT}$ ) were cross-calibrated.

\section{Image Evaluation}

Two board-certified specialists in nuclear medicine with 10 and $27 \mathrm{y}$ of clinical experience interpreted all datasets independently and resolved any disagreement by consensus.

The mean and maximum standardized uptake values $\left(\mathrm{SUV}_{\text {mean }}\right.$ and $\mathrm{SUV}_{\max }$, respectively) of lacrimal, parotid, submandibular, and sublingual glands; mediastinal blood pool (aortic arch); and liver, spleen, small proximal bowel, colon, kidneys, and gluteal musculature (as background) were analyzed at 1 and $3 \mathrm{~h}$ after injection in 15 patients. In 4 patients, the same procedure was additionally conducted at $5 \mathrm{~min}$, $2 \mathrm{~h}, 4 \mathrm{~h}$, and $5 \mathrm{~h}$ after injection.

With regard to the colon, SUV was measured at the localization with the highest radiotracer uptake, which was usually the descending part.

For calculation of the SUV, circular regions of interest were drawn around areas with focally increased uptake in transaxial slices and automatically adapted to a 3-dimensional volume of interest (VOI) at a $70 \%$ isocontour.
SUVs in images acquired at $3 \mathrm{~h}$ after injection were compared with those at $1 \mathrm{~h}$ after injection and defined as increasing, decreasing, or stable, with intensity changes of greater than $10 \%$, less than $-10 \%$, or between $-10 \%$ and $+10 \%$, respectively.

Lesions that were visually considered as suggestive for PCa were counted and analyzed with respect to their localization (local relapses, lymph node [LN], bone, and soft-tissue metastases) and to their $\mathrm{SUV}_{\text {mean }}$ and $\mathrm{SUV}_{\text {max }}$.

Any visible PCa lesion of a patient was counted and analyzed unless patients had more than 10 lesions. In such a case, a maximum of 10 lesions was analyzed after random selection. This kind of selection avoids an overestimation of SUVs because otherwisedominant lesions would be preferentially selected.

Tumor contrast was measured by dividing the $\mathrm{SUV}_{\text {mean }}$ of tumor lesions by the $\mathrm{SUV}_{\text {mean }}$ of the background (gluteal musculature) and by dividing the $\mathrm{SUV}_{\max }$ of tumor lesions by the $\mathrm{SUV}_{\max }$ of the background.

\section{Statistical Analysis}

The statistical distribution of $\mathrm{SUV}_{\text {mean }}$ and $\mathrm{SUV}_{\max }$ values was assessed visually and by Shapiro-Wilk tests and found to be approximately normal. Thus, SUVs of the above-mentioned organs and of the tumor lesions at 1 and $3 \mathrm{~h}$ after injection were compared using a paired-sample $t$ test.

Because PSA levels showed a skewed distribution, a 2-sided MannWhitney test was used to evaluate differences concerning PSA values between groups with and without pathologic findings in PET/CT.

A $P$ value of less than 0.05 was considered statistically significant.

\section{Radiation Dosimetry}

To find the optimal point of time for the diagnostic examination, the activity distribution of 4 patients was measured at $5 \mathrm{~min}, 1 \mathrm{~h}, 2 \mathrm{~h}, 3 \mathrm{~h}$, $4 \mathrm{~h}$, and $5 \mathrm{~h}$ after injection of ${ }^{68} \mathrm{Ga}$-PSMA-617. The data of these patients were used to estimate the internal radiation dose.

The activity distributions of the source organs were determined with the help of PMOD software (PMOD Technologies), which was

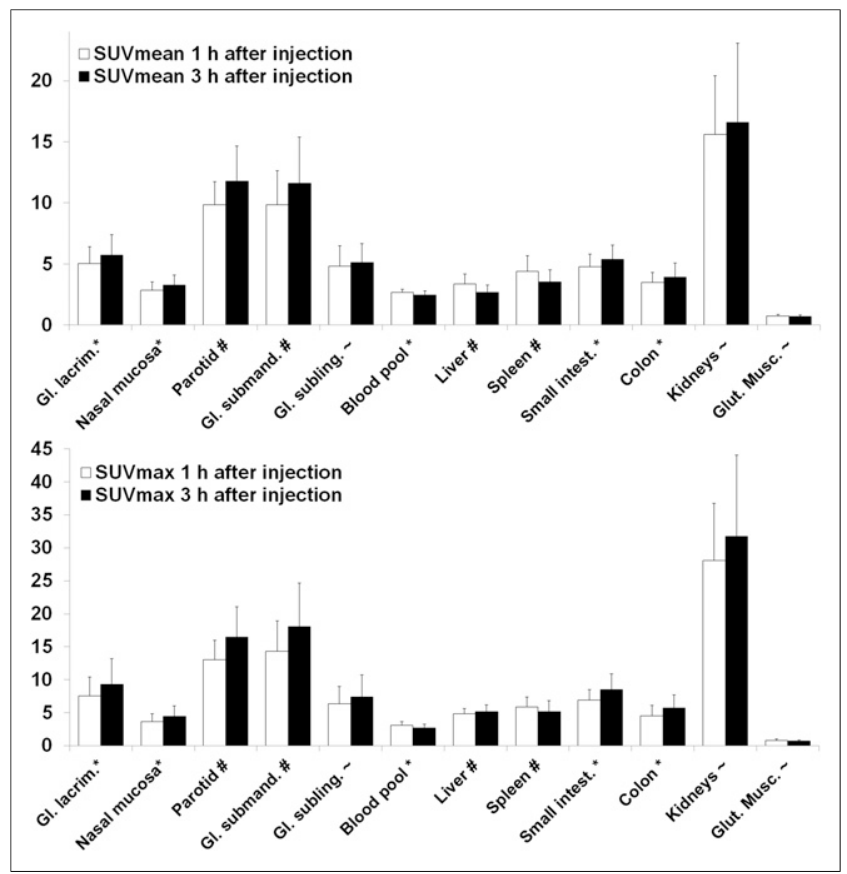

FIGURE 2. Average SUV $\mathrm{Sean}_{\text {men }}$ and SUV $\mathrm{V}_{\max }$ in different organs 1 and $3 \mathrm{~h}$ after injection. Significance of differences between 1 and $3 \mathrm{~h}$ ( $t$ test): ${ }^{\#} P<0.001 ;{ }^{*} P<0.05 ; \sim P>0.05$. Gl. = glandular; Glut. Musc. = gluteal musculature. 


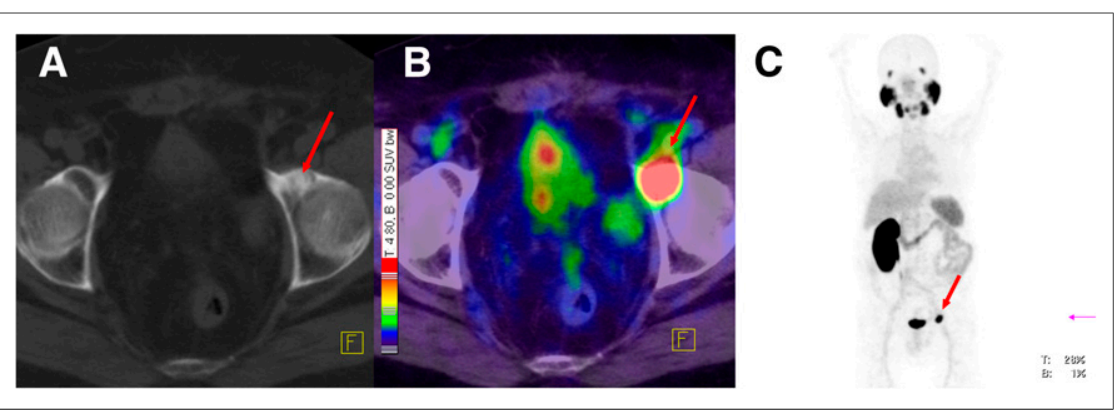

FIGURE 3. (A-C) ${ }^{68} \mathrm{Ga}-\mathrm{PSMA}-617 \mathrm{PET} / \mathrm{CT}$ of patient 11 at $1 \mathrm{~h}$ after injection. Red arrows point to a bone metastasis with SUV $\mathrm{max}_{\max }$ of 21.7 at $1 \mathrm{~h}$ and 32.6 at $3 \mathrm{~h}$ after injection. (A) Low dose CT. (B) Fusion of PET and CT. (C) MIP of PET/CT. MIP = maximum-intensity projection. added to the urinary bladder content calculated from the PET/CT measurements. The excreted activity (decay corrected) was subtracted from the remainder measured at the next PET/CT measurement.

\section{RESULTS}

None of the patients developed adverse events or clinically detectable pharmacologic effects. Figure 1 demonstrates the maximum-intensity projection of a patient with normal biodistribution of ${ }^{68} \mathrm{Ga}$ PSMA-617 at $3 \mathrm{~h}$ after injection.

Average $\mathrm{SUV}_{\text {mean }}$ and $\mathrm{SUV}_{\max }$ values of different tissues in all patients analyzed (1 used to define the VOIs in the PET images. The VOIs were chosen in the way that the whole activity of the organ was considered. Care needed to be taken to not interfere with the activity concentration of adjacent organs. The number of disintegrations in the organs divided by administered activity was estimated by integration of the timeactivity curves of the corresponding VOIs. This is the area under the time-activity curve normalized to the amount of activity administered and is termed residence time in the following sections as it is an established term in internal dosimetry.

After the residence times of the source organs were calculated, the organ doses and the effective dose per unit of administered activity were calculated using the OLINDA/EXM application (version 1.1) (26).

The urinary excretion was also considered. The patients were asked to collect the excreted urine before each PET/CT measurement. The activity of the urine was determined separately. This activity was

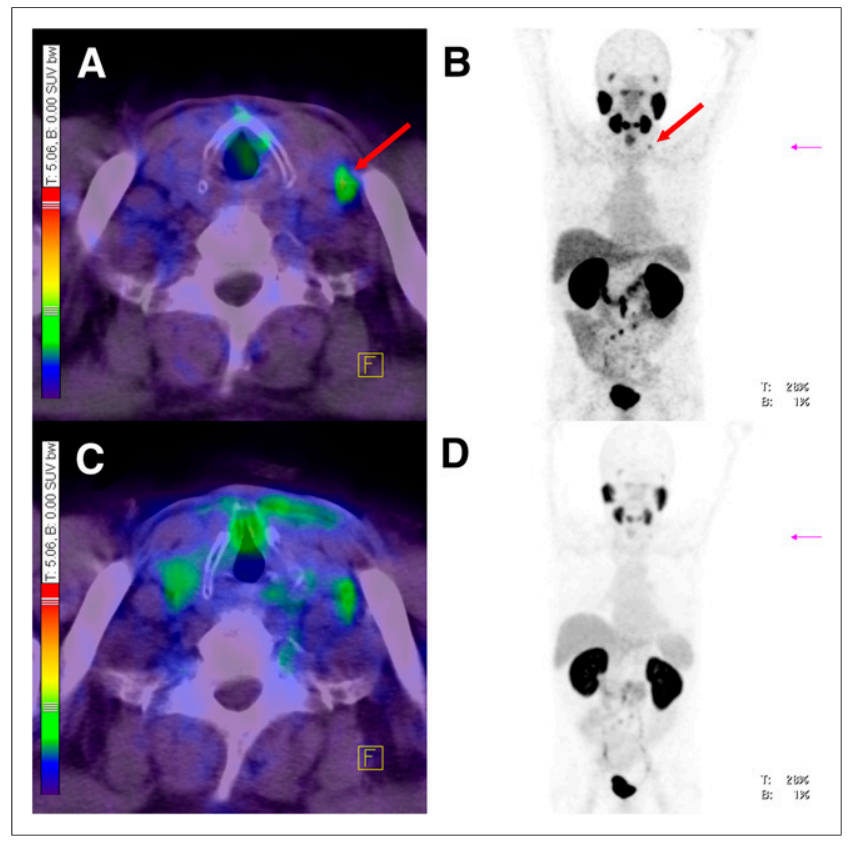

FIGURE 4. ${ }^{68} \mathrm{Ga}-\mathrm{PSMA}-617-\mathrm{PET} / \mathrm{CT}$ of patient 3 at $1 \mathrm{~h}(\mathrm{C}$ and $\mathrm{D})$ and $3 \mathrm{~h}$ after injection (A and B). Red arrows point to LN (Virchow's node), which was identified as metastasis in images at $3 \mathrm{~h}$ after injection only. In images at $1 \mathrm{~h}$ after injection, tracer accumulation was rated as artifact. In this patient, also 4 other LNs (retroperitoneal) were identified as metastases in images at $3 \mathrm{~h}$ after injection only. (A) Fusion of PET and CT $3 \mathrm{~h}$ after injection. (B) Maximum-intensity projection of PET/CT $3 \mathrm{~h}$ after injection. (C) Fusion of PET and CT $1 \mathrm{~h}$ after injection. (D) Maximumintensity projection of PET/CT $1 \mathrm{~h}$ after injection. and $3 \mathrm{~h}$ after injection) are summarized in Figure 2 and Supplemental Table 1 (supplemental materials are available at http://jnm. snmjournals.org). Intraindividual changes in SUVs between 1 and $3 \mathrm{~h}$ after injection (increase, decrease, and stable) were investigated in all patients. The most reproducible trend was registered in the spleen, with almost all patients showing a decrease in radiotracer uptake.

A statistically significant increase of $\mathrm{SUV}_{\text {mean }}$ at $3 \mathrm{~h}$ after injection was observed in the following organs: lacrimal glands $(+19.5 \% ; P<0.001)$, nasal mucosa $(+19.2 \% ; P=0.011)$, parotid $0.001)$, proximal small intestine $(+18.4 \% ; P=0.003)$, and colon $(+13.0 \% ; P=0.040)$. $\mathrm{SUV}_{\text {mean }}$ also increased in the sublingual glands $(+7.9 \% ; P=0.066)$ and kidneys $(+9.9 \% ; P=0.072)$, however, without statistical significance.

A statistically significant decrease of SUV $_{\text {mean }}$ between 1 and $3 \mathrm{~h}$ after injection was observed in the mediastinal blood pool $(-5.6 \% ; P=0.041)$ and liver $(-18.6 \% ; P<0.001)$. $\mathrm{SUV}_{\text {mean }}$ decreased also in the gluteal musculature $(-0.8 \% ; P=0.826)$, however, without being statistically significant.

A statistically significant increase of $\mathrm{SUV}_{\max }$ was detected in lacrimal glands $(+34.5 \% ; P=0.001)$, nasal mucosa $(+27 \%$; $P=0.003)$, parotid glands $(+32.1 \% ; P<0.001)$, submandibular $0.001)$, proximal small intestine $(+33.4 \% ; P<0.001)$, colon $(+27.3 \% ; P=0.003)$, and kidneys $(+17.0 \% ; P=0.002)$. An increase was also observed in the liver $(+7.3 \% ; P=0.090)$, without reaching statistical significance.

A statistically significant decrease of $\mathrm{SUV}_{\max }$ between 1 and $3 \mathrm{~h}$ after injection was observed in the mediastinal blood pool $(-12.9 \% ; P=0.001)$ and spleen $(-11.5 \% ; P=0.001)$. SUV $\max$ decreased also in the gluteal musculature $(-6.3 \% ; P=0.331)$, however, without being statistically significant.

In 14 of 19 patients (73.7\%), at least 1 lesion suspected of being a tumor was detected. Figures 3 and 4 and Supplemental Figures 1 and 2 show some representative PCa lesions. Among all lesions visually considered typical for $\mathrm{PCa}$, we selected 53 representative lesions for further analysis (Fig. 5). Of these, 39 were defined as LN metastases (in 8 different patients), 8 as bone metastases (in 2 different patients), 3 as local relapses (in 3 different patients), and 3 as primary tumors (in 2 different patients).

As demonstrated by Figure 5 and Supplemental Figure 3, SUV $\mathrm{Vean}_{\text {men }}$ and $\mathrm{SUV}_{\max }$ increased in 46 and 50 lesions, respectively; decreased in 3 and 2 lesions, respectively; and remained stable in 4 and 1 lesions, respectively, between 1 and $3 \mathrm{~h}$ after injection. In patient 3, 5 of overall 8 lesions (Fig. 5, lesions 11, 12, 14, 17, and glands $(+25.2 \% ; P<0.001)$, submandibular glands $(+24.2 \% ; P<$ glands $(+31.3 \% ; P<0.001)$, sublingual glands $(+19.4 \% ; P<$ 


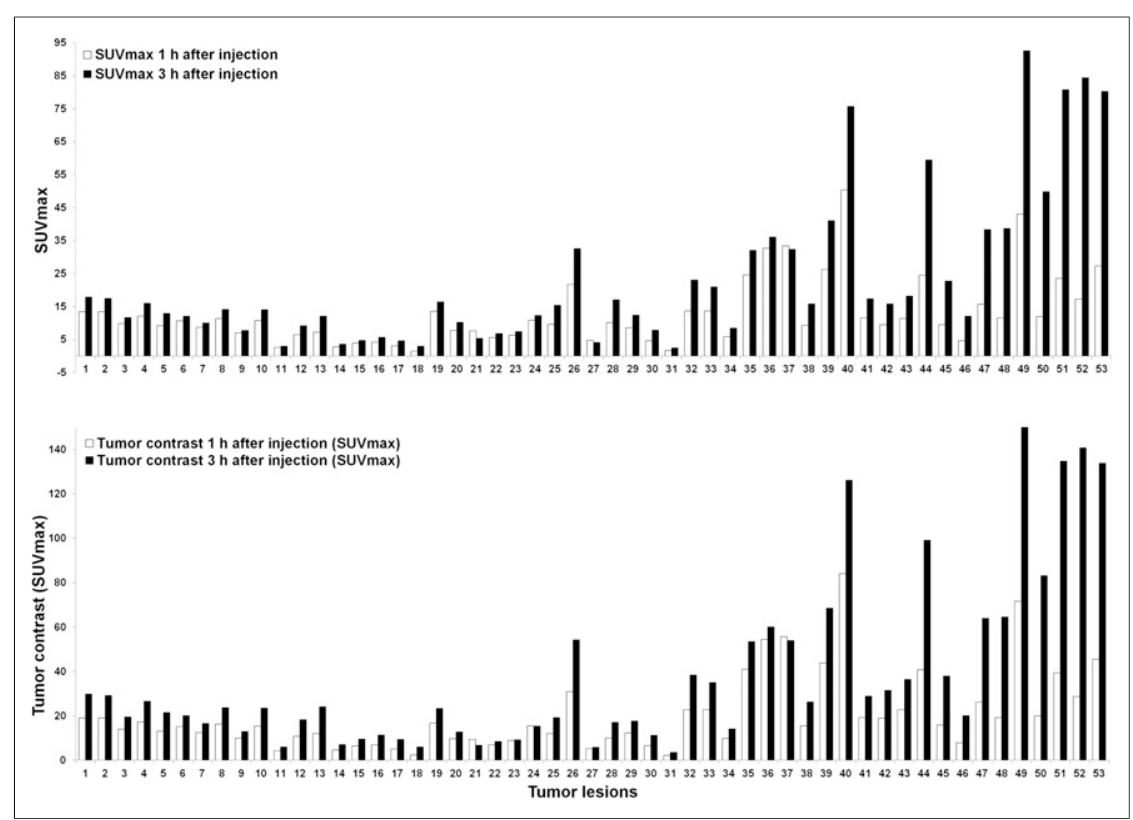

FIGURE 5. Average $\mathrm{SUV}_{\text {max }}$ in 53 representative $\mathrm{PCa}$ lesions and their ratio to background (contrast) 1 and $3 \mathrm{~h}$ after injection. Five of overall 8 lesions (lesions 11, 12, 14, 17, and 18) in patient 3 and 1 of overall 2 lesions (lesion 31) patient 16 were not visible in images at $1 \mathrm{~h}$ after injection because of low contrast.

18) and in patient 16, 1 of overall 2 lesions (Fig. 5, lesion 31) were not visible in the images at $1 \mathrm{~h}$ after injection because of low contrast.

The detailed SUVs of different types of PCa lesions at 1 and $3 \mathrm{~h}$ after injection are listed in Table 2. The highest SUVs were measured in bone metastases, followed by LN metastases, local relapses, and primary tumors.
Patients without pathologic findings $(n=$ 5) had a mean PSA of $0.5 \pm 0.5 \mathrm{ng} / \mathrm{mL}$ (range, $0.1-1.3 \mathrm{ng} / \mathrm{mL}$; median, $0.4 \mathrm{ng} / \mathrm{mL}$ ) and a median Gleason score of 7.0 (range, 7-8) and were injected with a mean of $189 \pm 71 \mathrm{MBq}$ of radiotracer (range, 68$255 \mathrm{MBq}$; median, $237 \mathrm{MBq}$ ).

Patients with pathologic findings $(n=$ 14) had a mean PSA of $7.3 \pm 6.6 \mathrm{ng} / \mathrm{mL}$ (range, 1.3-24.3 ng/mL) and a median Gleason score of 7 (range, 5-9) and were injected with a mean of $196.8 \pm 54 \mathrm{MBq}$ of radiotracer (range, 132-295 MBq).

There was no significant difference in Gleason score and injected amount of tracer (activity, measured in $\mathrm{MBq}$ ) between both groups (with/without pathologic findings in PET/CT). However, PSA levels were significantly lower $(P=0.002)$ in the group without pathologic findings in the ${ }^{68}$ Ga-PSMA-617 PET/CT.

Follow-up information was available for 10 patients. Among these, 6 received local treatment: 5 were treated with external radiation of PSMA-positive lesions (all of them demonstrated a decrease of PSA) and 1 was operated on (presented with a decrease of PSA thereafter). Two patients were treated by androgendeprivation therapy only, and 2 others did not receive any treatment after PET/CT.

The effective dose of ${ }^{68} \mathrm{Ga}$-PSMA-617 was determined in 4 patients. An average activity of $231 \mathrm{MBq}$ was injected intravenously. Figure 6 presents the uptake and contrast of all tumor lesions in relation to the different times after the injection of

TABLE 2

SUVs of Different Types of PCa at 1 and 3 Hours After Injection

\begin{tabular}{|c|c|c|c|c|c|c|}
\hline \multirow[b]{2}{*}{ Different types of PCa } & \multicolumn{3}{|c|}{${ }^{68} \mathrm{Ga}-\mathrm{PSMA}-617 \mathrm{PET} / \mathrm{CT}$ at $1 \mathrm{~h}$ after injection } & \multicolumn{3}{|c|}{${ }^{68} \mathrm{Ga}-\mathrm{PSMA}-617 \mathrm{PET} / \mathrm{CT}$ at $3 \mathrm{~h}$ after injection } \\
\hline & SUV & Range & Median & SUV & Range & Median \\
\hline $\begin{array}{l}\text { LN metastases } \\
\qquad(n=39)\end{array}$ & SUV $_{\text {mean }} 7.1 \pm 4.3$ & $1.4-22.0$ & 6.4 & SUV $_{\text {mean }} 9.9 \pm 2.4$ & $2.5-34.1$ & 7.7 \\
\hline $\begin{array}{l}\text { Bone metastases } \\
\qquad(n=8)\end{array}$ & SUV $_{\text {mean }} 9.4 \pm 7.5$ & $3.3-25.6$ & 5.9 & $\mathrm{SUV}_{\text {mean }} 16.9 \pm 12.5$ & $4.5-44.9$ & 12.5 \\
\hline $\begin{array}{l}\text { Local relapses } \\
\qquad(n=3)\end{array}$ & SUV $_{\text {mean }} 6.5 \pm 0.9$ & $5.9-7.5$ & 6.2 & SUV $_{\text {mean }} 7.7 \pm 0.6$ & $7.2-8.3$ & 7.7 \\
\hline Primary tumors $(n=3)$ & SUV $_{\text {mean }} 7.1 \pm 0.4$ & $6.8-7.3$ & 7.1 & SUV $_{\text {mean }} 11.7 \pm 1.1$ & $10.9-12.5$ & 11.7 \\
\hline $\begin{array}{l}\text { LN metastases } \\
\qquad(n=39)\end{array}$ & SUV $_{\max } 12.3 \pm 10.3$ & $1.4-50.4$ & 9.3 & $\mathrm{SUV}_{\max } 20.4 \pm 22.5$ & 2.5-84.4 & 12.3 \\
\hline $\begin{array}{l}\text { Bone metastases } \\
\qquad(n=8)\end{array}$ & SUV $_{\max } 17.8 \pm 12.0$ & $4.7-43.0$ & 13.9 & $\mathrm{SUV}_{\max } 43.3 \pm 24.8$ & $12.1-92.6$ & 38.6 \\
\hline $\begin{array}{l}\text { Local relapses } \\
\qquad(n=3)\end{array}$ & $\mathrm{SUV}_{\max } 11.1 \pm 2.1$ & $9.6-13.5$ & 10.1 & $\mathrm{SUV}_{\max } 16.3 \pm 0.9$ & $15.4-17.1$ & 16.4 \\
\hline $\begin{array}{l}\text { Primary tumors } \\
\qquad(n=3)\end{array}$ & $\mathrm{SUV}_{\max } 8.6 \pm 3.4$ & $4.8-11.4$ & 9.5 & $\mathrm{SUV}_{\max } 12.7 \pm 7.5$ & $4.1-18.2$ & 15.8 \\
\hline
\end{tabular}




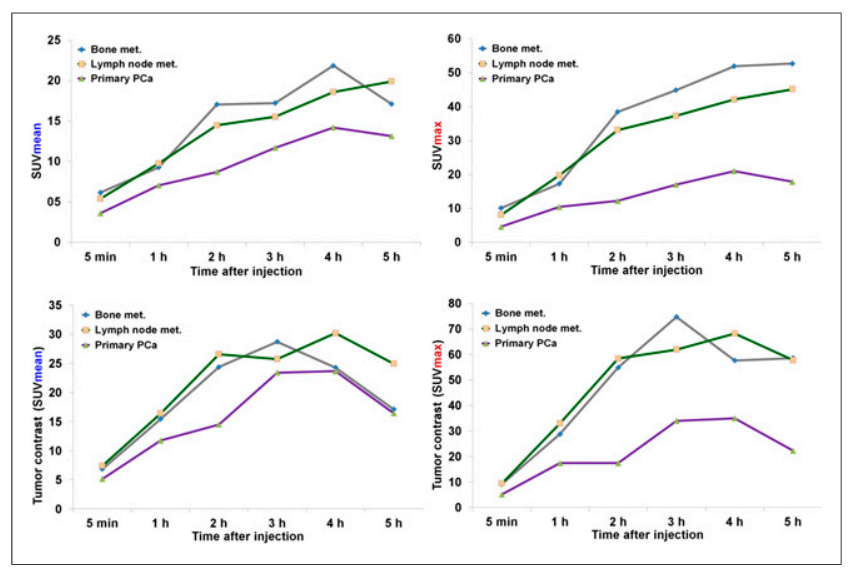

FIGURE 6. Development of SUVs and tumor contrast over time in all bone metastases $(n=7)$, LN metastases $(n=15)$, and primary tumors $(n=2)$ in patients 16-19. met. = metastases.

PSMA-617. As visible, most PCa lesions show an increase of uptake and contrast by time. Representatively, Figure 7 demonstrates maximum-intensity projections of a sequential PET/CT scan of patient 18 and the corresponding $\mathrm{SUV}_{\max }$ of 2 primary PCa lesions.

Table 3 provides the estimated residence times of ${ }^{68} \mathrm{Ga}$ of the selected source organs. The estimated organ doses in Table 4 show that the kidneys and the urinary bladder wall were the organs with the highest dose. As presented also by Table 4, the effective doses for patients $16-19$ were $0.021 \mathrm{mSv} / \mathrm{MBq} \pm 15 \%$ (maximum deviation), leading to an effective dose of $4.3 \mathrm{mSv}$ for an injected activity of $203 \mathrm{MBq}$ (mean injected activity of the 19 patients).

Supplemental Figures 4 and 5 show the decay-corrected radioactivity in the source organs as a function of time. The remainder was in the range of $65 \%-75 \%$ whereas the source organ distributions were of the order of magnitude of $15 \%$. The major contribution resulted from the kidneys, urinary bladder, and liver. The small intestine, upper large intestine, and spleen have been

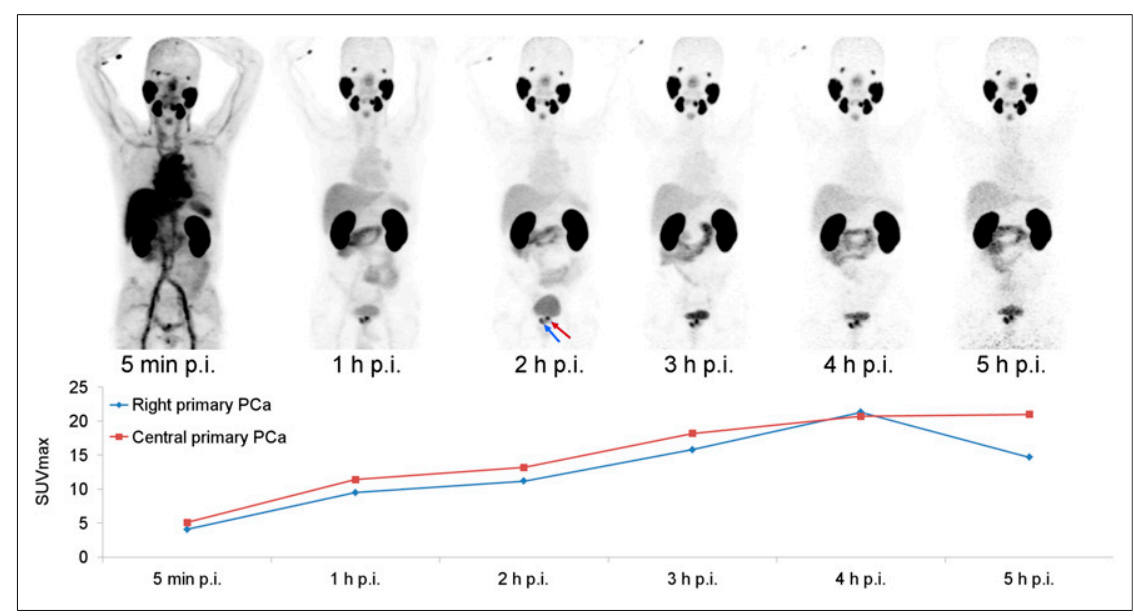

FIGURE 7. (Upper) Maximum-intensity projections of sequential PET/CT scan of patient 18 at different times after injection of $213 \mathrm{MBq}$ of ${ }^{68} \mathrm{Ga}-\mathrm{PSMA}-617$. Blue and red arrows point to 2 primary $\mathrm{PCa}$ lesions. (Lower) $\mathrm{SUV}_{\max }$ of the 2 primary $\mathrm{PCa}$ lesions at the different times. p.i. $=$ after injection. additionally considered as minor radiotracer uptake, with a mostly constant time course.

The activity of the lacrimal and salivary glands was below $2 \%$ of the injected activity and was considered in the remainder.

This approach has no effect for the estimation of the effective dose. When PSMA-617 is used with radioligand therapy, the organ doses of lacrimal and salivary glands should be considered individually.

\section{DISCUSSION}

The clinical introduction of PET imaging with the PSMA ligand ${ }^{68} \mathrm{Ga}-\mathrm{PSMA}-11$ has been regarded as a significant improvement in the diagnosis of $\mathrm{PCa}$. The hitherto existing results are highly promising and demonstrate that PSMA ligand PET/CT could be superior to other modalities for the diagnosis of recurrent PCa (19-23). However, more recently, ${ }^{68} \mathrm{Ga}-\mathrm{PSMA}-11$ has been structurally modified with the goal to allow labeling with several radiometals such as ${ }^{68} \mathrm{Ga},{ }^{111} \mathrm{In},{ }^{177} \mathrm{Lu}$, and ${ }^{90} \mathrm{Y}(24) .{ }^{177} \mathrm{Lu}$-labeled PSMA-617 is already in use for the treatment of metastatic $\mathrm{PCa}$ in multiple centers (25). So far, the performance of this novel PSMA ligand in the diagnosis of PCa in humans has not yet been evaluated. To assess the applicability of tumor imaging with ${ }^{68} \mathrm{Ga}$-PSMA-617, we evaluated the distribution of this theranostic substance in normal tissues, determined the radiotracer uptake in PCa lesions, and analyzed the radiation exposure of ${ }^{68} \mathrm{Ga}-\mathrm{PSMA}-617$ PET.

PSMA expression and uptake of radiolabeled PSMA ligands, mostly at low levels, has been reported for various normal tissues (21,27-29). In agreement with these data, our analysis demonstrated significant PSMA-617 uptake in the salivary glands and kidneys and to a lesser extent in lacrimal glands, liver, spleen, and bowel as well. In addition, the salivary and lacrimal glands showed a slight increment of radiotracer uptake between early and late images. This uptake is suggestive of radiotracer trapping and has already been shown as contributing to side effects during treatment with radiolabeled PSMA ligands (28). However, in most other organs our data demonstrate relatively stable uptake values between early and late images at levels similar to ${ }^{68} \mathrm{Ga}-\mathrm{PSMA}-11$, with the exception of the kidneys. The PSMA-617 uptake of the kidneys is significantly lower than ${ }^{68} \mathrm{Ga}-\mathrm{PSMA}-11$. Our observation is in accordance with preclinical studies in which a relatively low uptake and a fast clearance of the kidneys could be demonstrated: 113 percentage injected dose per gram at $1 \mathrm{~h}$ to 2.13 percentage injected dose at $24 \mathrm{~h} \mathrm{(24).} \mathrm{This} \mathrm{lower} \mathrm{uptake} \mathrm{and} \mathrm{faster}$ clearance result in a lower radiation exposure to the kidneys with consecutive advantages for patients who are referred to a PSMA-based radioligand therapy of metastatic PCa.

In addition, it might be hypothesized that the use of the same substance for both therapy and diagnosis can be a further advantage as it maximizes the precision of therapy response evaluation.

Among normal tissues, SUV decreased in the liver and spleen. Because PSMA expression is reported to be low in these organs (27), we hypothesized that radioactivity measured in these tissues partially reflects a blood-pool effect and is washed 
TABLE 3

Dosimetry Data and Residence Times of ${ }^{68} \mathrm{Ga}-\mathrm{PSMA}-617$

\begin{tabular}{lcccc}
\hline & \multicolumn{5}{c}{ Residence time $(\mathrm{Bq} \times \mathrm{h} / \mathrm{Bq})$ for patient } \\
\cline { 2 - 5 } Source organ & 16 & 17 & 18 & 19 \\
\hline Liver & 0.110 & 0.068 & 0.102 & 0.090 \\
\hline $\begin{array}{l}\text { Spleen } \\
\text { Kidneys }\end{array}$ & 0.014 & 0.006 & 0.003 & 0.013 \\
$\begin{array}{l}\text { Urinary } \\
\text { bladder }\end{array}$ & 0.153 & 0.053 & 0.196 & 0.125 \\
$\begin{array}{l}\text { Small } \\
\quad \text { intestine }\end{array}$ & 0.076 & 0.095 & 0.045 & 0.059 \\
$\quad \begin{array}{l}\text { Colon } \\
\text { Remainder }\end{array}$ & 0.042 & 0.033 & 0.052 & 0.004 \\
\hline
\end{tabular}

out as a result of the plasma clearance of the radiotracer. We cannot exclude that the ${ }^{68} \mathrm{Ga}$-labeled PSMA ligand as a small molecule redistributes from the intravascular compartment to the interstitial space with time, though.

In the preclinical literature, PSMA expression has been described for the proximal small intestine $(27,30)$. However, in agreement with our experiences with PSMA-11, all of our patients additionally showed PSMA-617 uptake in parts of the colon as well. We suggest that uptake in the colon reflects PSMA expression in neuroendocrine cell populations of colonic crypts or physiologic regeneration areas (27). In our study, there was no evidence of radiotracer clearance via the biliary tract. Furthermore, visualization of the gallbladder was not observed.

Radiotracer detection in nasal mucosa could be explained either by PSMA expression in areas of tissue regeneration or by a bloodpool effect.

Within all tumor lesions, bone metastases presented with the highest SUVs, followed by LN metastases, local relapses, and primary tumors. These results have to be interpreted with caution, though, as the number of lesion types is low and as there is a bias with regard to the number of lesions detected in the different patients. Larger studies are necessary to show which type of lesions present with the highest uptake of PSMA-617. However, our analysis of PSMA-11 uptake in 319 patients showed no significant difference of uptake in bone metastases $(n=359)$ and LN metastases ( $n=328$ ) (22).

Our study demonstrates that PCa lesions usually present with sufficient contrast already $1 \mathrm{~h}$ after the injection of ${ }^{68} \mathrm{Ga}-\mathrm{PSMA}-$ 617. However, images at $3 \mathrm{~h}$ after injection showed approximately $90 \%$ of the PCa lesions with significantly improved tracer uptake (SUVs) and contrast. This higher uptake and contrast resulted in the detection of 6 additional PCa lesions at $3 \mathrm{~h}$ after injection, compared with images at $1 \mathrm{~h}$ after injection ( 5 lesions in 1 patient and 1 lesion in another patient). Although these additional lesions did not change the tumor stage of the patients, we suggest obtaining images at times later than $1 \mathrm{~h}$ after injection. The increase of PSMA ligand uptake and tumor contrast by time have not only been demonstrated by the dosimetry data of this current study but also by our experiences with ${ }^{177} \mathrm{Lu}-\mathrm{PSMA}-617$ in the radioligand therapy of metastatic PCa (unpublished data of our institute, collected since 2011).

In addition, our previous analysis with PSMA-11 pointed out that most PCa lesions present with higher uptake and contrast in images obtained at $3 \mathrm{~h}$ after injection than at $1 \mathrm{~h}$ after injection. The higher uptake and contrast were observed in approximately $70 \%$ of the lesions (compared with $\sim 90 \%$ when using PSMA-617). In addition, all 65 lesions in all 37 patients of our previous study with ${ }^{68} \mathrm{Ga}$-PSMA-11 detected at $3 \mathrm{~h}$ after injection were already visible at $1 \mathrm{~h}$ after injection (21). That is to say, for ${ }^{68} \mathrm{Ga}-$ PSMA-11 obtaining images at $1 \mathrm{~h}$ after injection seems to be sufficient.

The above-mentioned results indicate that PSMA-617 presents with slower pharmacokinetics. Also considering the SUVs in Figure 6, we suggest performing PET/CT at 2-3 h after injection of ${ }^{68} \mathrm{Ga}$-PSMA-617. Images later than $3 \mathrm{~h}$ after injection can help to clarify unclear lesions because still many tumor lesions show increasing uptake and contrast at later times (Fig. 6). In this context, radionuclides with longer half-life, for example, ${ }^{18} \mathrm{~F}$, could show some advantages in imaging when used as a radiofluorinated PSMA-617 analog. On the other hand, a fast clearance of the radiolabeled molecule allows early imaging and does not need radionuclides with longer physical half-life. However, when using radiofluorinated PSMA ligands, a ${ }^{68} \mathrm{Ga}$ infrastructure does not need to be set up. In addition, the availability of cyclotron-based ${ }^{18} \mathrm{~F}$ is significantly higher than the generator-based ${ }^{68} \mathrm{Ga}$. Most recently, the team of Martin Pomper introduced an ${ }^{18} \mathrm{~F}$-labeled PSMA ligand, ${ }^{18}$ F-DCFPyL (14).

TABLE 4

Absorbed Organ Doses of ${ }^{68}$ Ga-PSMA-617 PET

\begin{tabular}{|c|c|c|c|c|}
\hline \multirow[b]{2}{*}{ Target organ } & \multicolumn{4}{|c|}{$\begin{array}{c}\text { Absorbed organ dose (mGy/MBq) for } \\
\text { patient }\end{array}$} \\
\hline & 16 & 17 & 18 & 19 \\
\hline Adrenals & 0.015 & 0.014 & 0.015 & 0.015 \\
\hline Brain & 0.010 & 0.011 & 0.010 & 0.011 \\
\hline Breasts & 0.010 & 0.011 & 0.010 & 0.010 \\
\hline Gallbladder & 0.015 & 0.014 & 0.016 & 0.015 \\
\hline Lower colon & 0.013 & 0.014 & 0.013 & 0.013 \\
\hline Small intestine & 0.019 & 0.015 & 0.024 & 0.015 \\
\hline Stomach & 0.013 & 0.013 & 0.013 & 0.013 \\
\hline Upper colon & 0.053 & 0.045 & 0.064 & 0.017 \\
\hline Heart & 0.012 & 0.012 & 0.012 & 0.012 \\
\hline Kidneys & 0.239 & 0.085 & 0.305 & 0.196 \\
\hline Liver & 0.033 & 0.022 & 0.032 & 0.028 \\
\hline Lungs & 0.011 & 0.012 & 0.011 & 0.012 \\
\hline Muscle & 0.011 & 0.012 & 0.011 & 0.012 \\
\hline Pancreas & 0.014 & 0.014 & 0.015 & 0.015 \\
\hline Red marrow & 0.010 & 0.010 & 0.010 & 0.010 \\
\hline Osteogenic cells & 0.015 & 0.017 & 0.015 & 0.016 \\
\hline Skin & 0.009 & 0.010 & 0.009 & 0.010 \\
\hline Spleen & 0.040 & 0.020 & 0.015 & 0.039 \\
\hline Testes & 0.011 & 0.012 & 0.011 & 0.012 \\
\hline Thymus & 0.011 & 0.012 & 0.011 & 0.012 \\
\hline Thyroid & 0.011 & 0.012 & 0.011 & 0.011 \\
\hline Urinary bladder & 0.098 & 0.121 & 0.062 & 0.080 \\
\hline Total body & 0.013 & 0.013 & 0.013 & 0.013 \\
\hline $\begin{array}{l}\text { Effective dose } \\
\qquad(\mathrm{mS} / \mathrm{MBq})\end{array}$ & 0.023 & 0.018 & 0.022 & 0.020 \\
\hline
\end{tabular}


Few PCa lesions decreased in SUV and contrast in later images (Fig. 5). Although the reason remains unclear, we speculate that some tumors show a reduced internalization rate of the PSMA ligand. Further studies are mandatory to clarify this observation.

PSMA-negative prostate carcinoma seems to be rare $(31,32)$. Consequently, the question remains why more patients do not present with a pathologic PET/CT in our retrospective analysis. Low or even absent PSMA expression and small tumor lesions could be sufficient explanations as to why not every patient of our collective presented with a pathologic ${ }^{68} \mathrm{Ga}$-PSMA-617 PET/CT finding.

The question remains which ${ }^{68} \mathrm{Ga}$-labeled version of PSMAtargeted radioligand, ${ }^{68} \mathrm{Ga}$-PSMA-11 or ${ }^{68} \mathrm{Ga}-\mathrm{PSMA}-617$, can be more recommended for diagnosing PCa. Usually the clinical routine is designed to conduct different PET scans at $1 \mathrm{~h}$ after injection only (e.g., ${ }^{18}$ F-FDG, DOTA conjugates, PSMA-11, ${ }^{18}$ F-DOPA). In this context, patients with multiple scans and later images require complex planning as they otherwise would disturb the clinical routine. Therefore, PSMA-11 with its putatively faster clearance provides a clear advantage. It remains unclear if PSMA-617, with its higher binding affinity and internalization, could detect more PCa lesions in a reasonable time window after injection than PSMA-11. Because of the same molecular effects, we believe that both PSMA ligands show also the same specificity for PCa. Overall, a study with a direct intraindvidual comparison between both ligands is mandatory to clarify which ligand is superior. Besides all mentioned considerations, we believe that centers that integrate ${ }^{68} \mathrm{Ga}$-PSMA617 into their clinical routine will be able to provide an excellent tool to diagnose $\mathrm{PCa}$ with vast scientific possibilities.

One limitation of our presented analysis is the lack of systematic histopathologic investigations of PET-positive lesions. However, since ${ }^{68} \mathrm{Ga}$-PSMA ligand PET/CT was introduced, the available data indicate that any uptake of PSMA ligands above local background in CT-morphologic-visible lesions is highly specific for $\mathrm{PCa}$ and, thus, has to be regarded as PCa unless otherwise proven. In this context, none of the lesions examined for this analysis was unclear: they all were typical for PCa. This statement is also supported by the results of the follow-up: patients who received targeted radiation therapy or lymphadenectomy of PET-positive lesions after the PET/ CT all presented with a decrease of PSA.

With regard to the dosimetry analysis, most of the injected activity could be considered to be homogeneously distributed in the remainder. The highest activity accumulation was found in the urinary bladder, the kidneys, and the small intestine. An average effective dose of $0.021 \mathrm{mSv} / \mathrm{MBq}$ was estimated. For instance, a low-dose ${ }^{68} \mathrm{Ga}$-PSMA-617 PET/CT with an administered activity of $203 \mathrm{MBq}$ results in an effective overall dose of $4.3 \mathrm{mSv}$ (PET) + $3.5 \mathrm{mSv}$ (lowdose CT), which equals $7.8 \mathrm{mSv}$. These results are similar compared with other most recently introduced PSMA ligands $(14,33)$.

\section{CONCLUSION}

This analysis presents the biodistribution and tumor uptake of ${ }^{68}$ Ga-PSMA-617 in patients. Within healthy organs, kidneys and salivary glands demonstrated the highest radiotracer uptake whereas lacrimal glands, liver, spleen, and bowel showed relatively moderate uptake. ${ }^{68} \mathrm{Ga}$-PSMA-617 shows lesions of PCa with high contrast, especially in late images. Maximum contrast of tumor lesions is usually seen between 3 and $4 \mathrm{~h}$ after injection. The radiation exposure of a PET scan with ${ }^{68} \mathrm{Ga}$-PSMA-617 is approximately $0.021 \mathrm{mSv} / \mathrm{MBq}$.

\section{DISCLOSURE}

The costs of publication of this article were defrayed in part by the payment of page charges. Therefore, and solely to indicate this fact, this article is hereby marked "advertisement" in accordance with 18 USC section 1734 . The research in this study was funded by a Klaus-Tschira-Foundation grant (no. 00.198.2012). Ali Afshar-Oromieh has received honoraria from Siemens Healthcare for 1 educational talk. No other potential conflict of interest relevant to this article was reported.

\section{ACKNOWLEDGMENTS}

We express our gratitude to our staff, in particular Kirsten Kunze and Stephanie Biedenstein.

\section{REFERENCES}

1. Jemal A, Bray F, Center MM, Ferlay J, Ward E, Forman D. Global cancer statistics. CA Cancer J Clin. 2011;61:69-90.

2. Siegel R, Ma J, Zou Z, Jemal A. Cancer statistics, 2014. CA Cancer J Clin. 2014;64:9-29.

3. Mease RC, Foss CA. MG P. PET imaging in prostate cancer: focus on prostatespecific membrane antigen. Curr Top Med Chem. 2013;13:951-962.

4. Foss CA, Mease RC, Cho SY, Kim HJ, Pomper MG. GCPII imaging and cancer. Curr Med Chem. 2012;19:1346-1359.

5. Chang SS, Gaudin PB, Reuter VE, O'Keefe DS, Bacich DJ, Heston WD. Prostate-specific membrane antigen: much more than a prostate cancer marker. Mol Urol. 1999;3:313-320.

6. Chang SS, O'Keefe DS, Bacich DJ, Reuter VE, Heston WD, Gaudin PB. Prostate-specific membrane antigen is produced in tumor-associated neovasculature. Clin Cancer Res. 1999;5:2674-2681.

7. Chang SS, Reuter VE, Heston WD, Bander NH, Grauer LS, Gaudin PB. Five different anti-prostate-specific membrane antigen (PSMA) antibodies confirm PSMA expression in tumor-associated neovasculature. Cancer Res. 1999;59:3192-3198.

8. Tagawa ST, Milowsky MI, Morris M, et al. Phase II study of lutetium-177labeled anti-prostate-specific membrane antigen monoclonal antibody J591 for metastatic castration-resistant prostate cancer. Clin Cancer Res. 2013;19:51825191.

9. Barrett JA, Coleman RE, Goldsmith SJ, et al. First-in-man evaluation of 2 highaffinity PSMA-avid small molecules for imaging prostate cancer. $\mathrm{J} \mathrm{Nucl} \mathrm{Med}$. 2013;54:380-387.

10. Hillier SM, Maresca KP, Femia FJ, et al. Preclinical evaluation of novel glutamateurea-lysine analogues that target prostate-specific membrane antigen as molecular imaging pharmaceuticals for prostate cancer. Cancer Res. 2009;69:6932-6940.

11. Maresca KP, Hillier SM, Femia FJ, et al. A series of halogenated heterodimeric inhibitors of prostate specific membrane antigen (PSMA) as radiolabeled probes for targeting prostate cancer. J Med Chem. 2009;52:347-357.

12. Hillier SM, Maresca KP, Lu G, et al. ${ }^{99 \mathrm{~m} T c-l a b e l e d ~ s m a l l-m o l e c u l e ~ i n h i b i t o r s ~ o f ~}$ prostate-specific membrane antigen for molecular imaging of prostate cancer. $J$ Nucl Med. 2013;54:1369-1376.

13. Banerjee SR, Pullambhatla M, Foss CA, et al. ${ }^{64} \mathrm{Cu}$-labeled inhibitors of prostate-specific membrane antigen for PET imaging of prostate cancer. J Med Chem. 2014;57:2657-2669.

14. Szabo Z, Mena E, Rowe SP, et al. Initial evaluation of [F]DCFPyL for prostatespecific membrane antigen (PSMA)-targeted PET imaging of prostate cancer. Mol Imaging Biol. 2015;17:565-574.

15. Ray Banerjee S, Pullambhatla M, Foss CA, et al. Effect of chelators on the pharmacokinetics of ${ }^{99 \mathrm{~m}} \mathrm{Tc}$-labeled imaging agents for the prostate-specific membrane antigen (PSMA). J Med Chem. 2013;56:6108-6121.

16. Cho SY, Gage KL, Mease RC, et al. Biodistribution, tumor detection, and radiation dosimetry of ${ }^{18} \mathrm{~F}-\mathrm{DCFBC}$, a low-molecular-weight inhibitor of prostatespecific membrane antigen, in patients with metastatic prostate cancer. $J \mathrm{Nucl}$ Med. 2012;53:1883-1891.

17. Eder M, Neels O, Muller M, et al. Novel preclinical and radiopharmaceutical aspects of $\left[{ }^{68} \mathrm{Ga}\right] \mathrm{Ga}-\mathrm{PSMA}-\mathrm{HBED}-\mathrm{CC}$ : a new PET tracer for imaging of prostate cancer. Pharmaceuticals (Basel). 2014;7:779-796.

18. Eder M, Schafer M, Bauder-Wust U, et al. ${ }^{68} \mathrm{Ga}$-Complex lipophilicity and the targeting property of a urea-based PSMA inhibitor for PET imaging. Bioconjug Chem. 2012;23:688-697. 
19. Afshar-Oromieh A, Haberkorn U, Schlemmer HP, et al. Comparison of PET/CT and PET/MRI hybrid systems using a ${ }^{68} \mathrm{Ga}$-labelled PSMA ligand for the diagnosis of recurrent prostate cancer: initial experience. Eur J Nucl Med Mol Imaging. 2014;41:887-897.

20. Afshar-Oromieh A, Zechmann CM, Malcher A, et al. Comparison of PET imaging with a Ga-labelled PSMA ligand and F-choline-based PET/CT for the diagnosis of recurrent prostate cancer. Eur J Nucl Med Mol Imaging. 2014;41:11-20.

21. Afshar-Oromieh A, Malcher A, Eder M, et al. PET imaging with a $\left[{ }^{68} \mathrm{Ga}\right]$ galliumlabelled PSMA ligand for the diagnosis of prostate cancer: biodistribution in humans and first evaluation of tumour lesions. Eur J Nucl Med Mol Imaging. 2013;40:486-495.

22. Afshar-Oromieh A, Avtzi E, Giesel FL, et al. The diagnostic value of PET/CT imaging with the ${ }^{68} \mathrm{Ga}$-labelled PSMA ligand HBED-CC in the diagnosis of recurrent prostate cancer. Eur J Nucl Med Mol Imaging. 2015;42:197-209.

23. Eiber M, Maurer T, Souvatzoglou M, et al. Evaluation of hybrid ${ }^{68} \mathrm{Ga}$-PSMA ligand PET/CT in 248 patients with biochemical recurrence after radical prostatectomy. J Nucl Med. 2015;56:668-674.

24. Benešová M, Schafer M, Bauder-Wust U, et al. Preclinical evaluation of a tailormade DOTA-conjugated PSMA inhibitor with optimized linker moiety for imaging and endoradiotherapy of prostate cancer. J Nucl Med. 2015;56:914-920.

25. Kratochwil C, Giesel FL, Eder M, et al. $\left[{ }^{177} \mathrm{Lu}\right]$ lutetium-labelled PSMA ligandinduced remission in a patient with metastatic prostate cancer. Eur J Nucl Med Mol Imaging. 2015;42:987-988.
26. Stabin MG, Sparks RB, Crowe E. OLINDA/EXM: the second-generation personal computer software for internal dose assessment in nuclear medicine. $\mathrm{J} \mathrm{Nucl}$ Med. 2005;46:1023-1027.

27. Silver DA, Pellicer I, Fair WR, Heston WD, Cordon-Cardo C. Prostate-specific membrane antigen expression in normal and malignant human tissues. Clin Cancer Res. 1997;3:81-85.

28. Zechmann CM, Afshar-Oromieh A, Armor T, et al. Radiation dosimetry and first therapy results with a ${ }^{124} \mathrm{I} /{ }^{131} \mathrm{I}$-labeled small molecule (MIP-1095) targeting PSMA for prostate cancer therapy. Eur J Nucl Med Mol Imaging. 2014;41: 1280-1292.

29. HpaF. The Human Protein Atlas website. http://www.proteinatlas.org/search/ hpaf. Accessed September 9, 2015.

30. Maraj BH, Aldersley MA, Markham AF. Prostate-specific membrane antigen expression in the duodenum: implications in coeliac disease and immunotherapy for prostate cancer. Lancet. 1998;351:1559-1560.

31. Mannweiler S, Amersdorfer P, Trajanoski S, Terrett JA, King D, Mehes G. Heterogeneity of prostate-specific membrane antigen (PSMA) expression in prostate carcinoma with distant metastasis. Pathol Oncol Res. 2009;15:167-172.

32. Bostwick DG, Pacelli A, Blute M, Roche P, Murphy GP. Prostate specific membrane antigen expression in prostatic intraepithelial neoplasia and adenocarcinoma: a study of 184 cases. Cancer. 1998;82:2256-2261.

33. Herrmann K, Bluemel C, Weineisen M, et al. Biodistribution and radiation dosimetry for a novel probe targeting prostate specific membrane antigen for imaging and therapy ( $\left.{ }^{68} \mathrm{Ga}-\mathrm{PSMA} \mathrm{I} \& \mathrm{~T}\right) . \mathrm{J}$ Nucl Med. 2015;56:855-861. 